\title{
Chromophobe Renal Cell Carcinoma, Oncocytoma and Clear Cell Carcinoma: A Compartive Immunohistochemical Study
}

\author{
MOHAMMED ABD ELHAMID, M.Sc.*; MOHEBAT H. GOUDA, M.D.*; TAGHREED ABD ELSAMEE, M.D.*; \\ NEHAL S. ZAFER, M.D.* and MAHMMOUD ELBAZ, M.D.** \\ The Department of Pathology, Faculty of Medicine, Benha University* and Department of Pathology, Urology \& \\ Nephrology Center, Mansoura University**
}

\begin{abstract}
Background: Renal oncocytoma, chromophobe RCC, and conventional RCC (granular cell type) have different prognosis. The differentiation between them sometimes is difficult and may cause a diagnostic dilemma.
\end{abstract}

Aim of Study: To reveal the better immunohistochemical diagnostic markers for differentiation between Chromophobe Renal Cell Carcinoma (ChRCC), Clear Cell Renal Cell Carcinoma (CCRCC), and oncocytoma.

Material and Methods: We reviewed one hundred and fifty cases of renal cell carcinoma: ChRCC (100 case), CCRCC ( 25 cases) and RO ( 25 cases). We carried out comprehensive immunohistochemical profiling using Hales Colloidal Iron stain (HCI), and 6 markers: Vimentin, CK7, CD 10, CD 117. EpCAM, and S100.

Results: Our results demonstrated a statistically significant difference in the expression of Hales colloidal iron among the studied renal tumors ( $p$-value $<0.0001$ ) as $94 \%$ of cases of chromophobe renal cells carcinoma showed positive staining for Hales colloidal iron, but cases of clear cell renal cell carcinoma and oncocytoma showed no staining for Hales colloidal iron stain. All cases of ChRCC were negative for vimentin. $72 \%$ of CCRCC and $8 \%$ of oncocytoma showed cytoplasmic positivity for vimentin. This difference in the expression was statistically significant ( $p$-value $<0.0001$ ). $76 \%$ of ChRCC cases showed cytoplasmic immunoreactivity to CK7, while $8 \%$ of CCRCC and $4 \%$ of oncocytoma showed such cytoplasmic immunoreactivity for CK7. These results were statistically significant with $p$-value $<0.0001$. We found that CD 10 showed statistically significant correlation with tumour type with $p$-value 0.025 . CD 117, EpCAM, S100A1 showed statistically significant correlation with tumor type with $p$-value $<0.0001$.

Conclusion: We concluded that the best panel of markers that can differentiate between the three studied renal tumour types by calculating sensitivity and specificity of each marker in each tumour type we found that the best panel is Vimentin, EpCAM and S100A1.

Correspondence To: Dr. Mohammed Abd Elhamid, The Department of Pathology, Faculty of Medicine, Benha University
Key Words: CD1 0-CK7-Chromophobe renal cell carcinoma - Clear cell renal cell carcinoma - CCRCC S100A1 - EpCAM - Immunohistochemistry Renal oncocytoma - Vimentin.

\section{Introduction}

RENAL Cell Carcinoma (RCC) ratio is about $90 \%$ of all of the renal tumors that affects adults in both sexes. Generally, it represents the 12 th most common neoplasm in males and 17 th in females. In developed countries like Japan, it is incidence resembles non-Hodgkin lymphoma representing the 6 th, but in less developed areas it represents the $16^{\text {th }}$. Regarding females, it represents the 12 th and 17 th in developed and developing countries respectively [1,2]. In Egypt the male to female ratio is about $2: 1$ and the incidence in men is about $1.53 \%$ representing the 10 th most common cancers in male and in women is about $.97 \%$ representing the 17 th most common cancers in females [3].

There is a great prognostic significance of histological types of renal cell carcinoma; so it is essential to detect the type of renal malignant epithelial neoplasm in a correct way, and to discriminate between them and the benign neoplasm [4]. There are many overlaps in the histopathological features between renal neoplasms, this overlaps make the accurate diagnosis of the histological subtypes a challenge in some cases. The correct diagnosis of renal cell neoplasm is usually depends on the cytological, architectural, IHC and cytogenatic features $[\mathbf{5 , 6}]$.

The incidence of chromophobe renal cell carcinoma is relatively low, represents about $5 \%$ of kidney neoplasm [7]. Discrimination between chromophobe RCC and other kidney neoplasms depending on $\mathrm{H} \& \mathrm{E}$ staind slides and Hales colloidal iron stained section is possible in many 
cases, but overlaps of the cytoarchitectural features make the proper diagnosis a problem, even with the expeperienced pathologist [8,9].

Therefore, there is a great importence to find a fast and reliable IHC markers that can be applied in the pathology labs. Recently, few, but effective IHC markers have been identified to differentiate between chromophobe RCC and oncocytoma, clear RCC. Vimentin, CD 10 and cytokeratin (CK7) were reportedby many studies as effecint IHC markers to make such differentiation, but their results were conflicted [10] . Recently, many studies have concluded that CD 117 and EpCAM were also helpful for discrimination, but no single marker can be used with great accurecy for this purpose. In conclusion, it is not reliable to depend on a single IHC marker to make such differentiation, especially if the method of interpretation of staining of this marker is not straight or with small tissue sample [11,12] .

\section{Aim of the work:}

This study aims to study the histopathological characters of chromophobe renal cell carcinoma with revision of its incidence and study the pattern of expression of different immunohistochemical markers in differentiation between chromophobe RCC, oncocytoma and clear RCC.

\section{Patients and Methods}

This was a retrospective study including retrieval of selected, previously diagnosed, formalin fixed paraffin embedded tissue sections from archival blocks of one hundred and fifty cases of renal cell carcinoma that were collected from the Department of Pathology, Urology and Nephrology Center, Mansoura University from 2004 up to 2013. The studied cases fulfilled the following criteria:

- Clinical data as regard patient's age, sex and site of the tumor that collected from hospital records and pathology reports.

- Cases undergone radical nephrectomy for the proper evaluation of tumor type, size, stage and lymph node status.

The cases are classified into 100 case of chromophobe renal cell carcinoma, 25 cases of clear renal cell carcinoma and 25 cases of oncocytoma.

\section{Histological review:}

Serial sections of 5 microns thickness were cut from each tissue block, one section was stained by Hematoxylin and Eosin $(\mathrm{H} \& \mathrm{E})$ to examine the histopathological features. The renal epithelial carcinoma specimens were graded by WHO nuclear grading 2016 and staged by TNM staging system (AJCC, 2018). Presence or absence of capsular and perirenal fat invasion and renal vein invasion by the tumor.

\section{Hale's colloidal iron staining method:}

Using the colloidal iron suspension of Rhinehart and Abu'l Haj.

\section{Immunohistochemical staining:}

The corresponding cell blocks were cut $4 \mu \mathrm{m}$ thick, were mounted on positively-charged slides, steps of staining followed the standard ABC (avidin-biotin complex) procedure using the Ultra Vision Detection System (Anti-polyvalent, HRP/ DAB, ready-to-use, Lab Vision corporation). Antigen retrieval was done with microwave treatment in $10 \mathrm{mM}$ citrate buffer (Neo-Markers, Cat. \# AP9003), $\mathrm{pH}$ 6.0. and stained with:

1-Anti-CD 10 (Clone GM003), mouse monoclonal antibody. (Genemed, USA).

2- Anti-CD117 (Clone CL-1657) mouse monoclonal antibody. (Novus, USA).

3- Anti-Vimentin (clone V9), mouse monoclonal antibody. (Genemed, USA). 4

4- Anti-CK7 (clone OV-TL 12/30), mouse monoclonal antibody. (Genemed, USA).

5- Anti-EpCam (Clone 60N5D8) mouse monoclonal antibody. (Novus, USA).

6- Anti-S 100A1 (clone 2C8B8), mouse monoclonal antibody. (Novus, USA).

7- Power stain 1.0 poly HRP/DAB kit for mouse and rabbit (Genemed, USA).

Table (1): The incubation and pre-treatment time were 30 minutes for all the immunostains. Appropriate positive and negative controls were included. The freshly prepared DAB-substratechromogen solution was applied.

Table (1): The Ag retrieval, incubation period and positive control for the IHC markers.

\begin{tabular}{llcl}
\hline Antibody & Ag retreival & $\begin{array}{c}\text { Incubation } \\
\text { period }\end{array}$ & Positive control \\
\hline Vimentin & Citrate buffer & 30 minutes & $\bullet$ Lymph node. \\
CK7 & Citrate buffer & 30 minutes & $\bullet$ Lunge adenocarcinoma. \\
CD 10 & Citrate buffer & 30 minutes & $\bullet$ Follicular lymphoma. \\
CD117 & Citrate buffer & 30 minutes & $\bullet$ Lymphoid cells ion \\
& & & normal stomach. \\
EpCam & Citrate buffer & 30 minutes & $\bullet$ Normal human colon. \\
S100 & Citrate buffer & 30 minutes & $\bullet$ Brain tissue. \\
\hline
\end{tabular}


Interpretation of special stain and IHC staining:

I- Hale's colloidal iron stain:Cytoplasmic acid mucopolysaccharides and sialomucins stained deep blue and nuclei stained pink-red.

II- Immuno-reactivity: Positive immunoreactivity gives a brown cytoplasmic staining in tumor cells. The whole section was examined to detect the score. Semiquantitative assessment of the staining intensity was scored as 0 (negative), 1 (weak), 2 (moderate), and 3 (strong). The percentage of tumor cells that showed positivity for the marker relative to the whole carcinoma area was calculated, then the cases were scored as $0(0 \%), 1$ (1 to $25 \%)$, 2 (26 to $50 \%), 3$ (51 to $75 \%$ ), and 4 (76 to $100 \%$ ), based on such percentage. The sum of the intensity and extent score was used as the final staining score (0 to 7$)$, tumors having a final staining score of >or equal 3 were considered to be positive $[\mathbf{1 , 1 3}]$

\section{IV- Statistical analysis:}

Data analysis was performed using the IBMSPSS version 21 for windows software package. The association between any two tumour characteristics was estimated by Chi-square test and $p$ value of $\leq 0.05$ was considered significant and of $<0.001$ was considered highly significant. To study the simultaneous effects of different prognostic factors on survival, Cox proportional hazards analysis was used for the significant variables by Log rank test.

\section{Results}

A- Clinical and histopathological features of the studied cases:

- Insignificant statistical correlation between patients age and tumour type was found with $p$ value: 0.906 .

- We found insignificant statistical correlation between patients' sex and tumour type with $p$ value: 0.383 .

- There was significant statistical correlation between tumour size and tumour type with $p$-value: 0.001 .

- No significant Statistical correlation between tumour site and tumour type was found ( $p$-value: 0.653 ).

- Nuclear grade showed high statistical correlation with tumour type with $p$-value: $<0.0001$.

- LNs metastasis didn't significantly correlate with tumour type, with $p$-value: 0.375 .

- Invasion of renal capsule didn't significantly correlate with tumour type, with $p$-value: 0.450 .
- There was no significant statistical correlation between invasion of renal sinus fat and tumour type with $p$-vale: 0.042 .

- There was no statistical correlation between malignant renal vein thrombosis and tumour type with $p$-value: 0.263 .

- There was significant statistical correlation between tumour type and tumour stage with $p$-value $<0.0001$.

Table (2): Clinical and histopathological features of the studied cases.

\begin{tabular}{|c|c|c|c|c|c|c|c|}
\hline \multirow{2}{*}{$\begin{array}{l}\text { Clinical and } \\
\text { histopathological } \\
\text { features }\end{array}$} & \multicolumn{2}{|c|}{ Ch RCC } & \multicolumn{2}{|c|}{ CCRCC } & \multicolumn{2}{|c|}{ Oncocytoma } & \multirow{2}{*}{$\begin{array}{c}p- \\
\text { value }\end{array}$} \\
\hline & No & $\%$ & No & $\%$ & No & $\%$ & \\
\hline Mean age & \multicolumn{2}{|c|}{$51.7 \pm 12.5$} & \multicolumn{2}{|c|}{$52.7 \pm 11.6$} & \multicolumn{2}{|c|}{$51.8 \pm 11.6$} & 0.906 \\
\hline \multicolumn{8}{|l|}{ Sex: } \\
\hline Male & 57 & $57 \%$ & 20 & $80 \%$ & 15 & $60 \%$ & 0.383 \\
\hline Female & 43 & $43 \%$ & 5 & $20 \%$ & 10 & $40 \%$ & \\
\hline \multicolumn{8}{|l|}{ Size: } \\
\hline $1-4 \mathrm{~cm}$ & 11 & $11 \%$ & 5 & $20 \%$ & 7 & $28 \%$ & 0.001 \\
\hline $4-7 \mathrm{~cm}$ & 30 & $30 \%$ & 13 & $52 \%$ & 7 & $28 \%$ & \\
\hline $7-10 \mathrm{~cm}$ & 26 & $26 \%$ & 7 & $28 \%$ & 6 & $6 \%$ & \\
\hline$>10 \mathrm{~cm}$ & 33 & $33 \%$ & 5 & $20 \%$ & 5 & $5 \%$ & \\
\hline \multicolumn{8}{|l|}{ Site: } \\
\hline Upper pole & 28 & $28 \%$ & 10 & $40 \%$ & 3 & $12 \%$ & 0.653 \\
\hline Mid zone & 12 & $12 \%$ & 6 & $24 \%$ & 7 & $28 \%$ & \\
\hline Lower pole & 49 & $49 \%$ & 7 & $28 \%$ & 15 & $60 \%$ & \\
\hline Whole kidney & 11 & $11 \%$ & 2 & $8 \%$ & 0 & 0 & \\
\hline \multicolumn{8}{|l|}{ Nuclear grade: } \\
\hline GI & 36 & $36 \%$ & 10 & $40 \%$ & - & - & 0.0001 \\
\hline GII & 52 & $52 \%$ & 12 & $48 \%$ & - & - & \\
\hline GIII & 6 & $6 \%$ & 3 & $3 \%$ & - & - & \\
\hline GIV & 6 & $6 \%$ & 0 & 0 & - & - & \\
\hline \multicolumn{8}{|l|}{ LN metastasis: } \\
\hline Absent & 96 & $96 \%$ & 24 & $96 \%$ & - & - & 0.359 \\
\hline Present & 4 & $4 \%$ & 1 & $4 \%$ & - & - & \\
\hline \multicolumn{8}{|l|}{ Cap invasion: } \\
\hline Absent & 95 & $95 \%$ & 23 & $92 \%$ & - & - & 0.450 \\
\hline Present & 5 & $5 \%$ & 2 & $8 \%$ & - & - & \\
\hline \multicolumn{8}{|l|}{$R S$ invasion: } \\
\hline Absent & 81 & $81 \%$ & 20 & $80 \%$ & - & - & 0.042 \\
\hline Present & 19 & $19 \%$ & 5 & $20 \%$ & - & - & \\
\hline \multicolumn{8}{|l|}{ RV thrombosis: } \\
\hline Absent & 93 & $93 \%$ & 23 & $92 \%$ & - & - & 0.263 \\
\hline Present & 7 & $7 \%$ & 2 & $8 \%$ & - & - & \\
\hline \multicolumn{8}{|l|}{ Tumor stage: } \\
\hline SI & 41 & $41 \%$ & 17 & $68 \%$ & - & - & 0.0001 \\
\hline SII & 40 & $40 \%$ & 3 & $12 \%$ & - & - & \\
\hline SIII & 17 & $17 \%$ & 4 & $16 \%$ & - & - & \\
\hline SIV & 2 & $2 \%$ & 1 & $4 \%$ & - & - & \\
\hline
\end{tabular}

B- Results of special stain and IHC in the studied cases:

- There was a statistically significant difference in the expression of Hales colloidal iron among the studied renal tumors $(p$-value $<0.0001)$ (Table 3), Fig. (1D,E,F). 
- Vimentin showed statistically significant correlation with tumour type with $p$-value $<0.0001$ (Table 3), Fig. (1G,H,I).

- CK7 showed statistically significant correlation with tumor type with $p$-value $<0.0001$ (Table 3 ), Fig. (1J,K,L).

- CD10 showed statistically accepted significant correlation with tumour type with $p$-value 0.025 (Table 3), Fig. (2A,B,C).
- CD 117 showed statistically significant correlation with tumor type with $p$-value $<0.0001$ (Table 3 ), Fig. (2D,E,F).

- EpCAM showed statistically significant correlation with tumour type with $p$-value $<0.0001$ (Table $3)$, Fig. (2G,H,I).

- S100A1 showed statistically significant correlation with tumour type with $p$-value $<0.0001$ (Table 3), Fig. (2J,K,L).

Table (3): Results of special stain and IHC in the studied cases.

\begin{tabular}{llllllllll}
\hline & \multicolumn{2}{c}{ ChRCC } & \multicolumn{2}{c}{ CCRCC } & \multicolumn{2}{c}{ Oncocytoma } & Specificity & Sensitivity & $p$-value \\
\cline { 2 - 6 } & $+\mathrm{ve}$ & $-\mathrm{ve}$ & $+\mathrm{ve}$ & $-\mathrm{ve}$ & $+\mathrm{ve}$ & $-\mathrm{ve}$ & & & \\
\hline Colloidal iron & 94 & 6 & 0 & 25 & 0 & 25 & $100 \%$ & $94 \%$ & $<0.0001$ \\
Vimentin & 0 & 100 & 18 & 7 & 2 & 23 & $98 \%$ & $72 \%$ & $<0.0001$ \\
CK7 & 76 & 24 & 2 & 23 & 1 & 24 & $94 \%$ & $76 \%$ & $<0.0001$ \\
CD 10 & 50 & 50 & 23 & 2 & 2 & 23 & $58 \%$ & $92 \%$ & 0.05 \\
CD117 & 100 & 0 & 3 & 22 & 24 & 1 & $54 \%$ & $100 \%$ & $<0.0001$ \\
EpCAM & 95 & 5 & 0 & 25 & 0 & 25 & $100 \%$ & $95 \%$ & $<0.0001$ \\
S100A1 & 0 & 100 & 0 & 25 & 25 & 0 & $100 \%$ & $100 \%$ & $<0.0001$ \\
\hline
\end{tabular}

From this table we concluded that:

The best panel of markers that can differentiate between the three studied renal tumour types by calculating sensitivity and specificity of each marker in each tumour type we found that the best panel is Vimentin, EpCAM and S100A1.

\section{Discussion}

Renal oncocytoma, chromophobe RCC, and conventional RCC (granular cell type) have different prognosis in some cases discrimination between (ChRCC), oncocytoma and clear cell (conventional) renal cell carcinoma (eosinophilic variant) based on $\mathrm{H} \& \mathrm{E}$ slides alone is a big challange.

In the current research, we found a statistically significant difference in the expression of Hales colloidal iron among the studied renal tumors $(p$ value $<0.0001$ ) as $94 \%$ of cases of chromophobe renal cells carcinoma showed positive staining for Hales colloidal iron, but cases of clear cell renal cell carcinoma and oncocytoma showed no staining for Hales colloidal iron stain. Matched to our results, Skinnider, et al. [14] reported that in all cases of chromophobe RCC, more than $75 \%$ of cells showed a diffuse cytoplasmic HCI positivity, whereas a variable proportion of cells in 20 oncocytomas showed focal cytoplasmic staining, in a perimembranous, apical, or perinuclear pattern. Geramizadeh, et al. [13] concluded that Hale's colloidal iron staining with diffuse reticular fine cytoplasmic pattern was present in ChRCCs, but was absent in other subtypes and oncocytomas.
Also, Din, et al. [15] found that Hale's colloidal iron was positive in all cases of ChRCCs. Conversely, Abrahams, et al. [16] found that the difference in the expression of Hales colloidal iron among studied cases was not contributory.

As regard vimentin expression we found that all cases of ChRCC were negative for vimentin. $72 \%$ of CCRCC and $8 \%$ of oncocytoma showed cytoplasmic positivity for vimentin. This difference in the expression was statistically significant ( $p$ value $<0.0001$ ). Abrahams, et al., [16] reported that vimentin was useful but had low specificity (sensitivity 0.75 ; specificity 0.4 ) in differentiation between renal tumors.

Williams, et al., [17] reported that positive Vimentin ccRCC and positive CD9 positive in chRCC are the most reliable to differentiate between ccRCC and chRCC. The combination of vimentin negativity and $\mathrm{CD} 9$ positivity was found to distinguish chRCC from ccRCC with a sensitivity of $100.0 \%$ and a specificity of $95.2 \%$. Geramizadeh et al., [13] reported that Vimentin, CK7, CD10, Hale's colloidal iron can be used for the differential diagnosis of problematic epithelial tumors of kidney (CRCC, ChRCC and oncocytoma)-ChRCC and oncocytoma showed negative Vimentin, and CRCC showed positive expression. Also, Zhao, et al., [1] and Kürschner, et al., [8] found that Vimentin was effective in discrimination between clear cell RCC and chromophobe RCC and oncocytoma (87\% of clear cell RCC positive, negative in chromophobe, only focally positive in oncocytoma). Lüders, et al., [7] found that Renal Oncocytoma (RO) and 
ChRCC showed negative reaction for vimentin, while CCRCC were positive for vimentin. Similarly, Zhang, et al., [5] reported that Eosinophilic clear cell renal cell carcinoma mainly showed positive immunostaining for Vimentin. Din, et al., [15] found that Vimentin was negative in all cases of ChRCC. Williams, et al., [17] concluded that the combination of vimentin negativity and CD9 positivity was found to distinguish chRCC from ccRCC with a sensitivity of $100.0 \%$ and a specificity of $95.2 \%$.
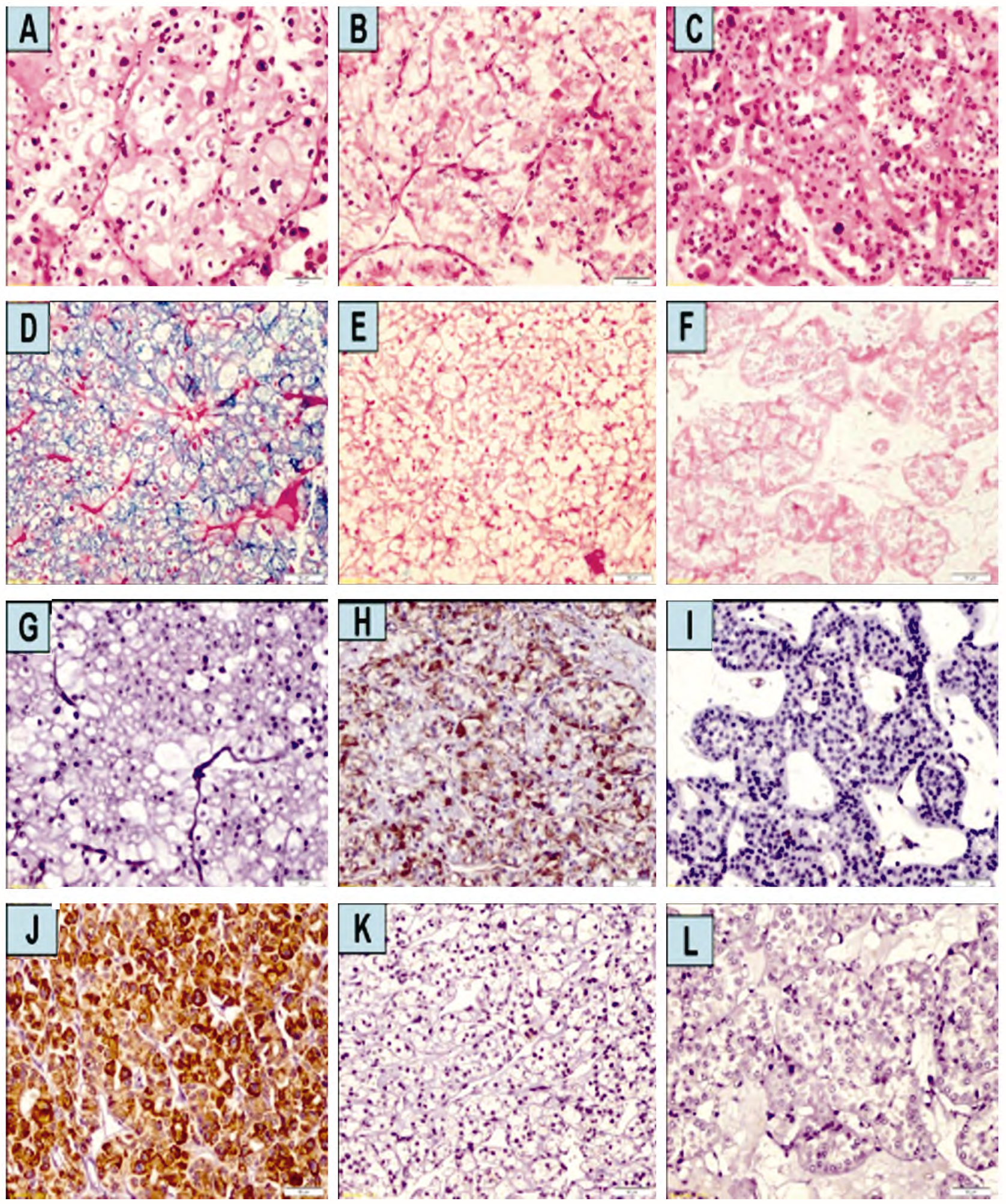

Fig. (1): (A, B, C) ChRCC, CCRCC, Oncocytoma respectively (H \& E X200). (D) ChRCC showed positive HCI with homogenous light blue cytoplasm and pink nuclei staining. (E, F) CCRCC, RO showed negative staining for HCI. (G, I) ChRCC, RO respectively showed negative expression for vimentin. (H) CCRCC showed cytoplasmic expression of vimentin. (J) ChRCC showed positive cytoplasmic expression for CK7. (K, L) CCRCC, RO showed: Negative expression ofCK7 (IHC X200). 

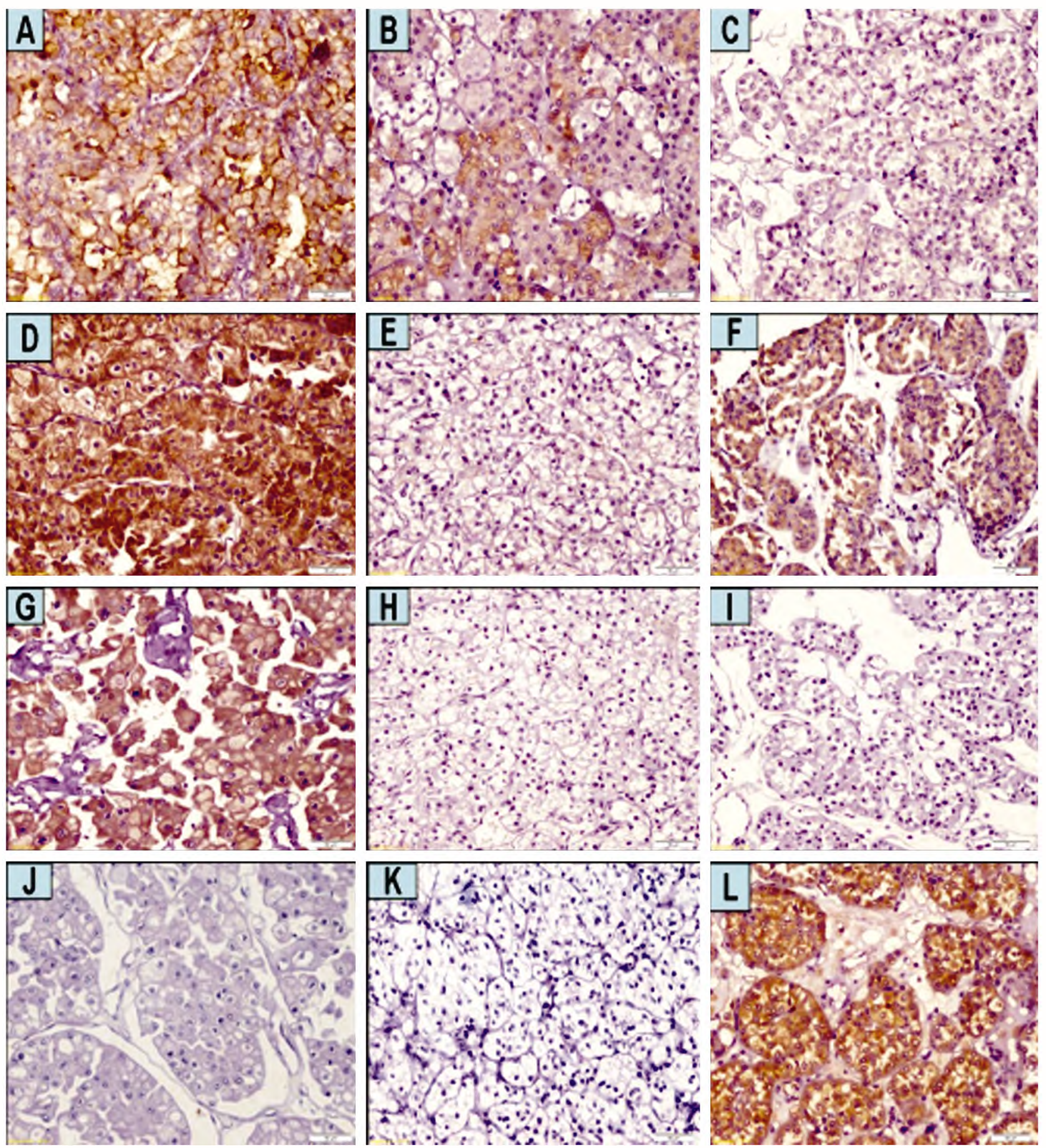

Fig. (2): (A) ChRCC showed strong cytoplasmic staining for CD 10 (IHC X200). (B) CCRCC showed strong membranous staining for CD 10 (IHC X200). (C) RO showed negative staining for CD 10 (IHC X200). (D) ChRCC showed intense cytoplasmic staining for CD 117 (IHC X200). (E) CCRCC showed negative cytoplasmic staining for CD 117 (IHC X200). (F) Oncocytoma showed intense cytoplasmic staining for CD 117 (IHC X200). (G) ChRCC showed moderate cytoplasmic staining for EpCAM (IHC X200). (H, I) CCRCC and oncocytoma respectively showed negative cytoplasmic staining for EpCAM (IHC X200). (J, K) ChRCC and CCRCC showed negative cytoplasmic staining for S100A1 (IHC X200). (L) Oncocytoma showed intense cytoplasmic staining for S100A1 (IHC X200).

Regarding CK7, 76\% of ChRCC cases showed cytoplasmic immunoreactivity to CK7, while $8 \%$ of CCRCC and $4 \%$ of oncocytoma showed such cytoplasmic immunoreactivity for CK7. These results were statistically significant with $p$-value
$<0.0001$. Regarding other markers, we found that CD 10 showed statistically significant correlation with tumour type with $p$-value 0.025. CD 117, EpCAM, S100A1 showed statistically significant correlation with tumor type with $p$-value $<0.0001$, 
and we concluded that the best panel of markers that can differentiate between the three studied renal tumour types by calculating sensitivity and specificity of each marker in each tumour type we found that the best panel is Vimentin, EpCAM and S 100A 1.

Abrahams, et al., [16] concluded that Keratin 7 had high sensitivity (0.83) but fairly low specificity (0.37) for CRCC. Zhao et al., 2015 reported that CK7 and CD117 were useful markers to distinguish ChRCC from renal oncocytoma and CRCC. Conversly, Yasir, et al. [18] found that 32\% of CCRCC cases were positive for $\mathrm{CK} 7$, in chRCC/RO group, $41 \%$ of cases showed positive expression of CK7, and concluded that combination of positive CD 10 and negative CK7 is considered the best immunohistochemical panel in distinguishing $\mathrm{ccRCC}$ from chRCC/RO. $\mathrm{Ng}$, et al., [19] found in a systematic review and meta-analysis of immunohistochemical biomarkers that differentiate chromophobe renal cell carcinoma from renal oncocytoma found that cytokeratin 7 (CK7) (11 studies, $\mathrm{n}=448$, pooled $\mathrm{OR}=44.22,95 \% \mathrm{CI} 22.52$ to $86.64, \mathrm{I}(2)=15 \%)$; S100A1 (4 studies, $n=124$, pooled $\mathrm{OR}=0.01,95 \%$ CI 0 to $0.03, \mathrm{I}(2)=0 \%$ ), and recommend a panel of IHC biomarkers including CK7, S100A1 in the differentiation of chRCC and RO. Luders, et al., [7] reported that for distinguishing between RO and ChRCC, CK7, claudin-7 (both strongly positive in $\mathrm{ChRCC}$ and negative or patchy positive in $\mathrm{RO}$ ) and epithelial cell adhesion molecule (EpCAM) can be used (positive in ChRCC, negative in RO).

Zhang, et al., [5] found that Eosinophilic clear cell renal cell carcinoma showed positive immunostaining for Vimentin, whereas negative for CK7 and CD117 in most cases (10/15). Kryvenko, et al., [9] found that in low-grade nonpapillary eosinophilic neoplasms, distinction between oncocytoma and low-grade RCC mostly rests on histomorphology; however, cytokeratin 7 immunostaining may be helpful, while in high-grade nonpapillary lesions, there is more of a role for ancillary techniques, including immunohistochemistry for cytokeratin 7, CA9, CD 10. Ng, et al., [2] found that there was significantly higher CK7 expression in chRCC compared to RO ( $p=0.03)$, and concluded that immunohistochemical staining and standard morphometry of CK7 and S100A1 can aid in the differentiation of chRCC and RO. Ma, et al., [4] reported that their findings provided further evidences that the expression of CK7 contribute to differentiate RCC from Oncocytomas. CK7 protein overexpression was found in RCC, low expression in any of Oncocytomas. CK7 is potentially an important renal tumor marker. Din, et al., [15] regarding ChRCC concluded that Hale's colloidal iron was positive in all cases. Immunohistochemical stain CK7 and CD117 were positive in $100 \%$ and $95.5 \%$ of cases respectively. Vimentin was negative in all cases.

\section{Conclusion:}

A small but a significant proportion of renal tumours with cells having eosinophilic cytoplasm cannot be classified, even by experienced pathologists, based alone on histology. In these cases it is important to use IHC markers with known sensitivity and specificity for the diagnosis.

\section{References}

1- ZHAO W., TIAN B., WU C., et al.: DOG1, cyclin D1, CK7, CD 117 and vimentin are useful immunohistochemical markers in distinguishing chromophobe renal cell carcinoma from clear cell renal cell carcinoma and renal oncocytoma. Pathol. Res. Pract., Apr., 211 (4): 303-7, 2015.

2- NG K.L., ELLIS R.J., SAMARATUNGA H., et al.: Utility of cytokeratin 7, S100A1 and caveolin-1 as immunohistochemical biomarkers to differentiate chromophobe renal cell carcinoma from renal oncocytoma. Transl. Androl. Urol., May; 8 (Suppl 2): S 123-S 137, 2019.

3- IBRAHIM A.S., KHALED H.S., MIKHAEL N., et al.: Cancer Incidence in Egypt: Results of the National Population-Based Cancer Registry Program. Journal of Cancer Epidemiology, 437971, 2014.

4- MA F.1, DAI L.1, WANG Z.1, et al.: Evaluating prognosis by CK7 differentiating renal cell carcinomas from oncocytomas can be used as a promising tool for optimizing diagnosis strategies. Oncotarget., Jul. 19; 7 (29): 4652846535, 2016.

5- ZHANG W.1, YU W.J.1, CHEN Y.Q.1 and KANG E.H.: Diagnostic utility of immunohistochemistry in differential diagnosis of renal tumors with oncocytic features. Zhonghua Bing Li Xue Za Zhi, Oct. 8, 45 (10): 692-7, 2016.

6- ROBINSON R.L.1, SHARMA A.1,2, BAI S.1, HENEIDI S., et al.: Comparative STAT3-Regulated Gene Expression Profile in Renal Cell Carcinoma Subtypes. Front Oncol., Feb. 26; 9: 72, 2019.

7- LÜDERS C.1 and KRISTIANSEN G.2: Oncocytoma versus chromophobe renal cell carcinoma: Is there something in between? Pathologe, Mar., 37 (2): 153-8, 2016.

8- KÜRSCHNER G., ZHANG Q., CLIMA R., et al.: Renal oncocytoma characterized by the defective complex I of the respiratory chain boosts the synthesis of the ROS scavenger glutathione. Oncotarget., Nov. 11; 8 (62): 105882-904, 2017.

9- NG K.L., MORAIS C., BERNARD A., et al.: A systematic review and meta-analysis of immunohistochemical biomarkers that differentiate chromophobe renal cell carcinoma from renal oncocytoma. J. Clin. Pathol., Aug., 69 (8): 661-71, 2016.

10- KRYVENKO O.N.1, JORDA M., ARGANI P., et al.: Diagnostic approach to eosinophilic renal neoplasms. Arch. Pathol. Lab. Med., Nov., 138 (11): 1531-41, 2014. 
11- CONNER J.R.1, HIRSCH M.S.1, JO V.Y., et al.: HNF1 $\beta$ and S100A1 are useful biomarkers for distinguishing renal oncocytoma and chromophobe renal cell carcinoma in FNA and core needle biopsies. Cancer Cytopathol., May; 123 (5): 298-305, 2015

12- WOBKER S.E.1,2 and WILLIAMSON S.R.: Modern Pathologic Diagnosis of Renal Oncocytoma. J. Kidney Cancer VHL, Oct. 9, 4 (4): 1-12, 2017.

13- GERAMIZADEH B.1, RAVANSHAD M. and RAHSAZ M.: Useful markers for differential diagnosis of oncocytoma, chromophobe renal cell carcinoma and conventional renal cell carcinoma. Indian J. Pathol. Microbiol., Apr.Jun., 51 (2): 167-71, 2008.

14- SKINNIDER B.F.1 and JONES E.C.: Renal oncocytoma and chromophobe renal cell carcinoma. A comparison of colloidal iron staining and electron microscopy. Am. J. Clin. Pathol., Jun., 111 (6): 796-803, 1999.

15- DIN N.U.1, FATIMA S. and AHMAD Z.: Chromophobe renal cell carcinoma: A morphologic and immunohisto- chemical study of 45 cases. Ann. Diagn. Pathol., Dec., 17 (6): 508-13, 2013

16- ABRAHAMS N.A., MacLENNAN G.T., KHOURY J.D., et al.: Chromophobe renal cell carcinoma: A comparative study of histological, immunohistochemical and ultrastructural features using high throughput tissue microarray. Histopathology, Dec., 45 (6): 593-602, 2004.

17- WILLIAMS G.M.1 and LYNCH D.T.2: Renal Oncocytoma. StatPearls [Internet]. Treasure Island (FL): StatPearls Publishing, Apr. 4, 2019.

18- YASIR S.1, HERRERA L., GOMEZ-FERNANDEZ C., et al.: CD10+ and CK7/RON-immunophenotype distinguishes renal cell carcinoma, conventional type with eosinophilic morphology from its mimickers. Appl Immunohistochem. Mol. Morphol., Oct., 20 (5): 454-61, 2012.

19- NG K.L.1, DEL VECCHIO S.J.2, SAMARATUNGA H., et al.: Leptin and its receptor: Can they help to differentiate chromophobe renal cell carcinoma from renal oncocytoma? Pathology, Aug., 50 (5): 504-10, 2018.

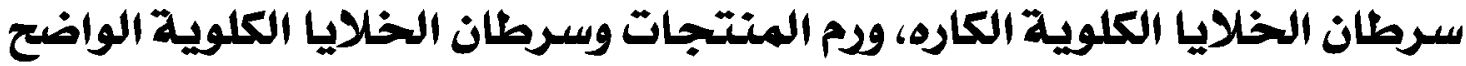

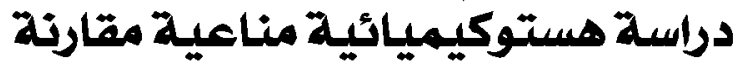

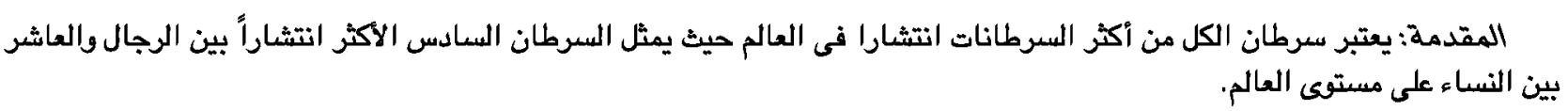

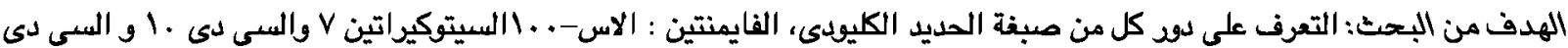

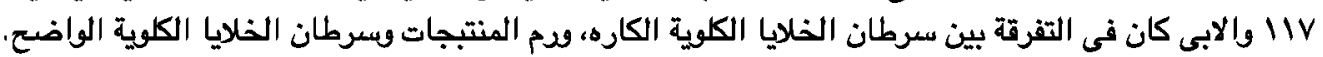

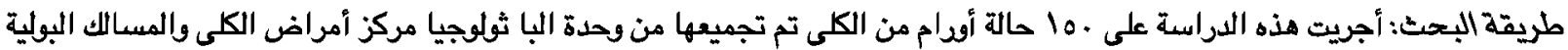

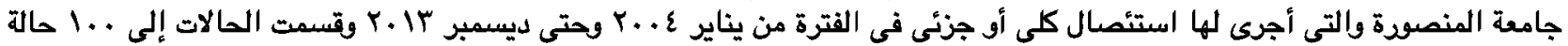

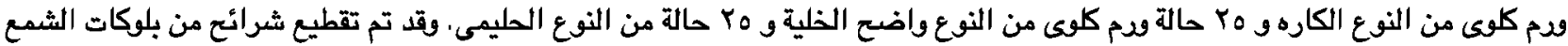

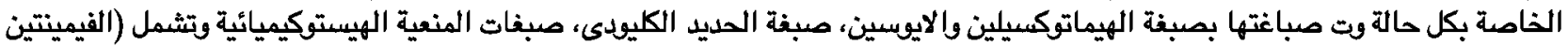

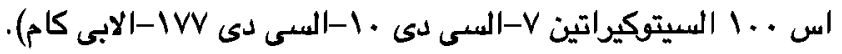

• لم تظهر حالات أودام الكلي واضح الخلية أو الحليمى أى تعبيراً إيجابياً لصبغة الحديد الكليودى فى حين أظهرت ع9٪ من أودام الكلى من

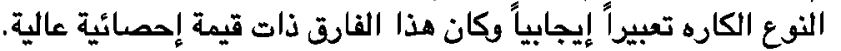

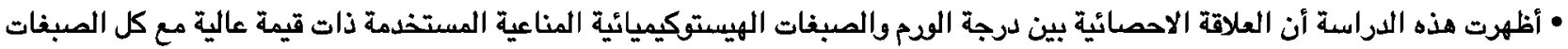

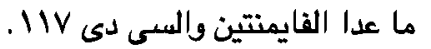

• العلاقة الاحصائية بين مرحلة الودم والصبغات الهيستوكيميائية المناعية المستخدمة ذات الهات قيمة عالية مع كل الصبغات الفايمنتين.

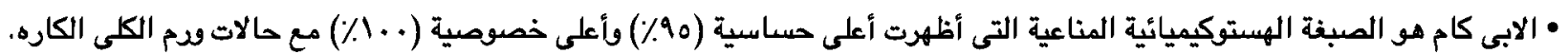

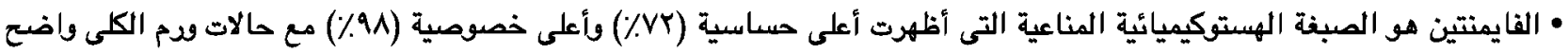
الخلية.

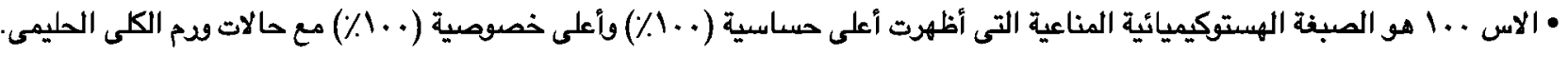

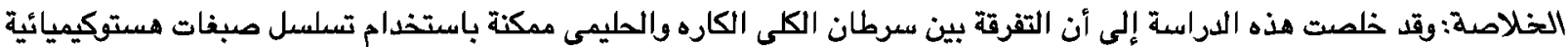

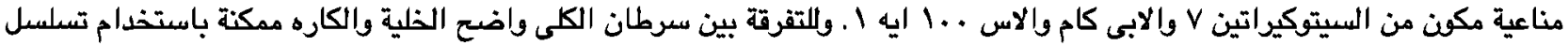

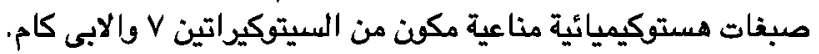

